7. med. Genet. (1968). 5, 29.

\title{
Ancell-Spiegler Cylindromas (Turban Tumours) and Brooke-Fordyce Trichoepitheliomas: Evidence for a Single Genetic Entity
}

\author{
J. P. WELCH,^ R. S. WELLS, and C. B. KERR \\ From the Division of Medical Genetics, Department of Medicine, The fohns Hopkins University School of Medicine, \\ Baltimore, Md, 21205, U.S.A., and Population Genetics Research Unit, Old Road, Headington, Oxford
}

It is generally believed that Ancell (1842) first described the inherited scalp tumours (Fig. 1) that later (Billroth, 1859) became known as dermal cylindromas. Subsequently the condition became associated with the name of Spiegler (1899) who reviewed extensive case material and introduced the term endothelioma capitis. There followed many descriptive accounts qualified by at least 20 different names of which only 'turban tumours' has remained in frequent usage. The term Ancell-Spiegler cylindromas will be employed here for lesions affecting mainly the scalp.

In September 1892 Brooke reported a family in which multiple small tumours involved the facial skin in some members. He favoured the term epithelioma adenoides cysticum. In December of the same year (1892), Fordyce described a mother and daughter with an apparently similar condition which he called multiple benign cystic epithelioma (Fig. 2). Both authors emphasized the origin of tumours from the basal cell layer of the epidermis and from hair follicles. The latter site appeared most significant to Jarisch (1894) who coined the term trichoepithelioma papulosum multiplex. All three descriptive terms are now regarded as synonymous and Brooke-Fordyce trichoepithelioma appears a reasonable compromise.

A clinical overlap between the two groups was noted early (Adamson, 1914), but it does not seem to have been established whether they are two separate conditions or variants of the same disorder first described by Ancell. Cockayne (1933) clearly believed both types of tumours to be manifestations of the same condition. It is our purpose to review and present new evidence supporting this hypothesis.

\footnotetext{
Received June 26, 1967

* Present address: Faculty of Medicine, Department of Paediatrics, Dalhousie University, Halifax, N.S., Canada.
}

Tumour dimorphism exists at the histological level (Watanabe, 1922; Gray and Helwig, 1963), but Savatard (1938) re-examined members of Brooke's original family at intervals and demonstrated histological features of each tumour type in the same affected person. Guggenheim (1962) described biopsy findings from a patient with both tumours; cords of basophilic cells surrounded by a hyaline membrane were obtained from scalp cylindromas and cystic material from nasal skin lesions contained horn cells typical of a trichoepithelioma.

Sweat duct adenomas (syringomas) may coexist with trichoepitheliomas (Ingels, 1935), but the relation between the two forms of tumours is not clear. Malignant changes (basal cell epithelioma) have been noted occasionally in cylindromas (Luger, 1949) and trichoepitheliomas (Ziprkowski and Schewach-Millet, 1966); but the situation is complicated by the frequent prior history of $x$-ray therapy in the former cases and possibly confusion with the inherited basal cell naevus syndrome in early reports (e.g. Adamson, 1914) of the latter.

Autosomal dominant inheritance has been demonstrated for Ancell-Spiegler cylindromas and BrookeFordyce trichoepitheliomas either singly or in combination (Chalstrey, 1955; Guggenheim, 1962). In one family there was segregation of isolated cylindromas in a mother and other maternal relatives, with trichoepitheliomas alone appearing in a son (Whiffen, 1963). Although an excess of males has been noted in some families (Fuss, 1928; Kerl, 1930), Guggenheim (1962) reviewed case reports of both conditions and demonstrated a predilection for females as compared to males, respectively 132 to 80 affected. Sibships in early reports frequently lack information on those supposedly unaffected, so that the apparent excess of females cannot be examined further in recorded material. In addition it is probable that women would be more likely to seek 

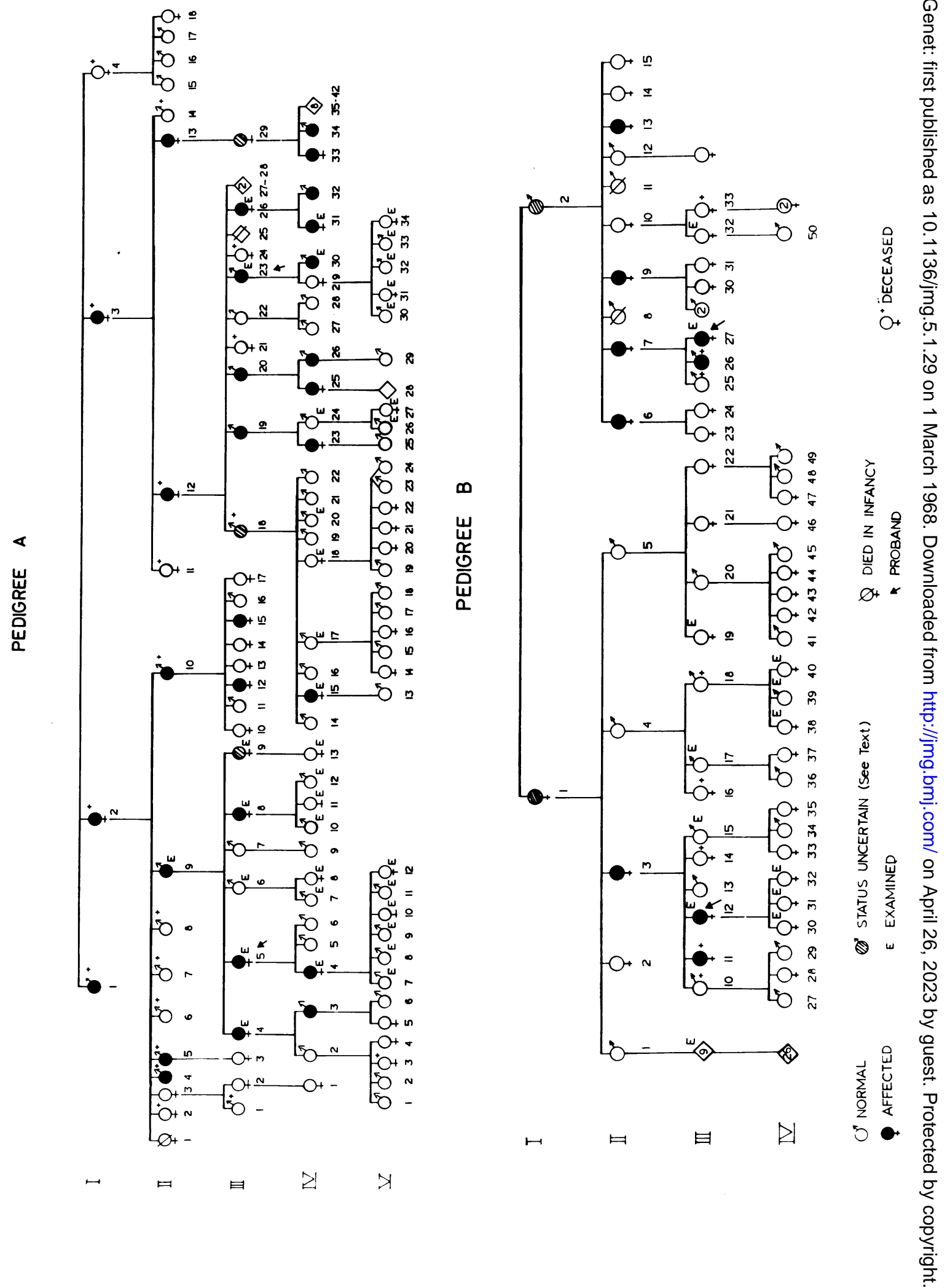
medical attention for cosmetic reasons. The relevance of endocrine factors, clearly a possibility, is not known.

The problem of whether Ancell-Spiegler cylindromas and Brooke-Fordyce epitheliomas represent different manifestations of the same mutation was examined further in the following investigation.

\section{Present Investigation}

Two large kindreds were studied; one (Pedigree A) in the U.S.A., the other (Pedigree B) in England. In each family, an attempt was made to collect objective information from as many members as possible. The status of each person with regard to evidence of clinical involvement is marked on the pedigree. Details of affected persons who were examined directly or for whom there was reliable information are given below; histological findings in sections of tumours from two affected members in each family are also described.

\section{Case Material}

Family A (Pedigree A). The family was ascertained through two probands, III.5 and III.23, who were quite unknown to each other. The first name and surname of those in generation I, obtained from II.9, were in agreement with similar information supplied by III.23. Both informants stated that the family originated from the Clarksburg area of West Virginia, and there can be little doubt that the probands were related.

II. 9 (F.C.). Male, born 1884 . Small tumours in the nasal region were first noted when aged 18. Many small tumours (diameter 1-3 mm.) were observed at this site and two nodules (diameter $2 \mathrm{~cm}$.) were detected in the scalp. He claimed that the latter had developed during the preceding 6 months.

II.13 (C.M.C.) Female. Examination of a family photograph revealed unequivocal tumours in the nasal region.

III.4 (P.C.) Female, born 1913. Tumours were noted from the age of 16 . There were innumerable lesions over the face and ears with a few small tumours (diameter $0.5 \mathrm{~cm}$.) in the scalp.

III.5 (F.C.L., JHH 649324). Female, born 1916. This woman was severely affected and first noted facial tumours when aged about 15 . There were many tumours around the eyes and nose (up to a diameter of $0.5 \mathrm{~cm}$.) and the external auditory meatuses were almost occluded. The scalp was covered with large hairless tumours (up to a diameter of $5 \mathrm{~cm}$.) and there was little normal scalp (Fig. 3).

III.8 (H.C.W.). Female, born 1927. There were several small tumours around the nose and one hairbearing lesion $(1 \mathrm{~cm}$. diameter $)$ in the scalp.

III.9 (A.C.H.). Female, born 1936. Regarded as probably affected, she had three small nodules (1-2 $\mathrm{mm}$. in diameter) on the face, one on the right side of the forehead and two below the right eye, but declined biopsy.

III.18 (G.S.). Male, born 1899, now deceased.
According to his normal children, IV. 17, IV.18, and IV.19, this man was not affected, but his affected daughter, IV.15, claimed that he had a single tumour in the nasal area.

III.23 (R.H.S., JHH 1069989). Male, born 1911. First noted small lumps on the face at about age 10 . He had many small tumours around the nose (Fig. 4) and 3 tumours (up to $2.5 \mathrm{~cm}$. in diameter) in the scalp.

III.26 (H.S. Van M.). Female, born 1917. Many small tumours in the nasal region had been noted since the age of 20. Despite her claims to the contrary, examination revealed a few small hair-bearing tumours of the scalp.

III.29 (C.V.). Female, born 1904. From pedigree evidence she must have possessed the mutant gene, but no information on her clinical status could be obtained.

IV.4 (B.C.C., JHH 649325). Male, born 1937. Facial tumours had been noted since the age of 12 , and were present in profusion around the nose. In addition a few lesions (up to $1 \mathrm{~cm}$. diameter) were located in the scalp.

IV.15 (M.S.K.). Female, born 1917. Tumours were present from an early age around the nose and eyes, but examination did not disclose any in the scalp.

IV.30 (R.A.S.). Male, born 1934. Since adolescence innumerable small tumours had been present in the nasal area and there were also several lesions of the scalp.

IV.31 (P. Van M.N.). Female, born 1937. Numerous small tumours around the nose had been noted since the age of 18. One tumour had been removed from the scalp but three others were detected on examination.

Family B (Pedigree B). This family was ascertained through two probands, III.12 and III.27, who each lived without knowledge of the other in a small town in the English Cotswolds. The genealogical link was traced through parish records which revealed that I.1 and I.2 were sibs. All members of generations I and II were dead, as were some in generations III (marked in Pedigree B). Several children in generation V were examined; all were normal and are not recorded on the pedigree.

Emigration from the area had disrupted the family but sufficiently reliable information was obtained from different informants to score as affected the absent or deceased members II.3, II.6, II.7, II.9, and II.13. Two others who died were medically recorded, namely III.11 who died from tetanus following puncture of a scalp cyst and III.26 who died from leukaemia in 1959.

III.12 (R.B.). Female, born 1901. Lesions were first noted on the trunk when aged 10 and had gradually extended, so by the age of 64 there were innumerable tumours over the entire body. Those on the trunk and limbs were small, but larger tumours (exceeding $2.5 \mathrm{~cm}$. in diameter) had been treated by $x$-ray therapy successfully, but not without prolonged and painful ulceration of the lesions.

III.27 (L.W.). Female, born 1903. Tumours appeared on the trunk at 25 years of age and the scalp was first involved 10 years later. Tumours from the 

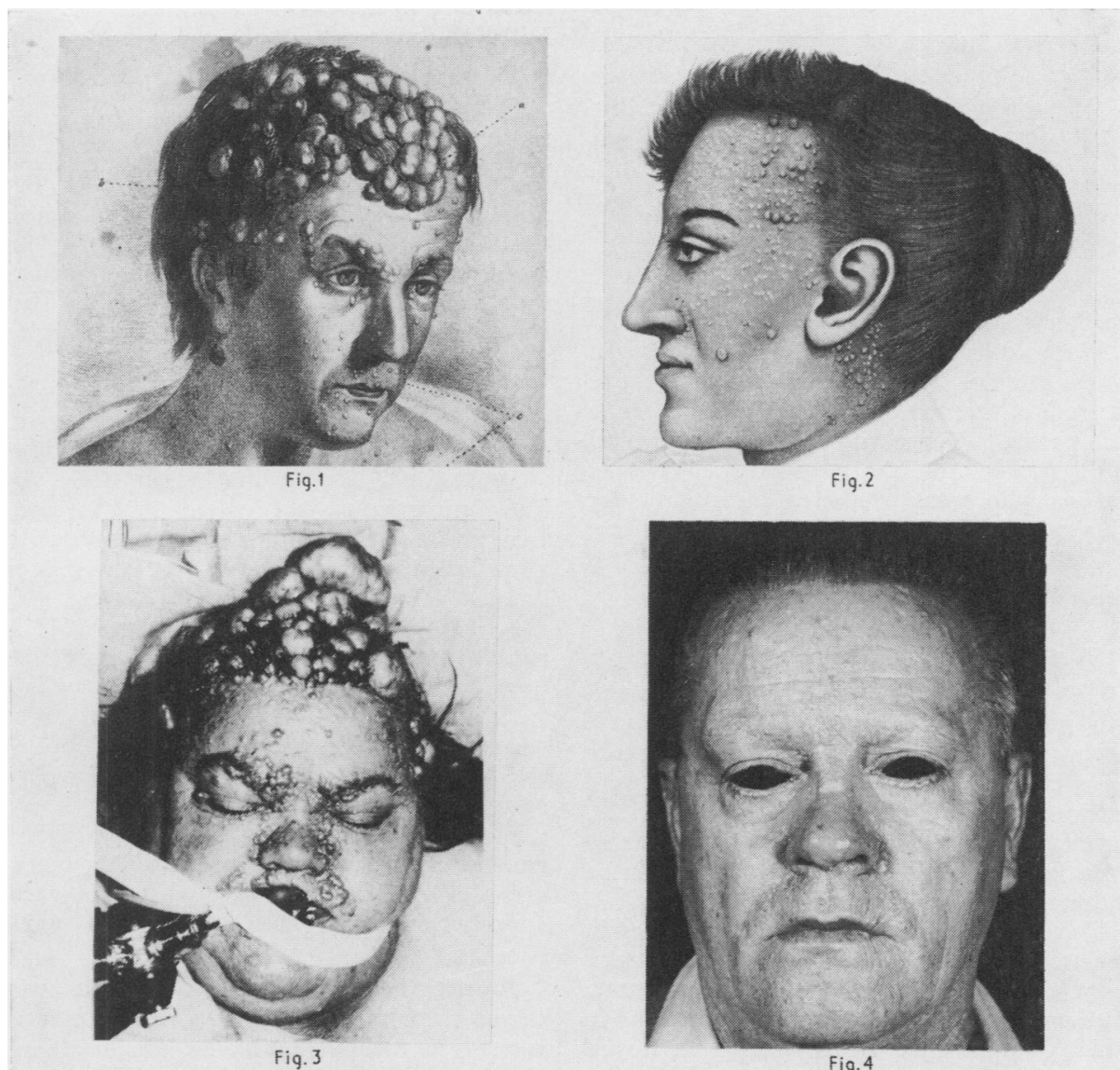
latter area had been excised surgically and the end result after skin grafting was most satisfactory.

\section{Histological Findings}

Tumour tissue was obtained by biopsy from all four probands; multiple sites were examined in the probands of Family A, but only material from scalp lesions was available in Family B.

Microscopical appearances typical of cylindromas were observed in scalp tumours from all probands; typical findings of epithelial cell islands surrounded by a hyaline membrane are demonstrated in Fig. 5 . Lesions from other sites in members of Family A had a more differentiated appearance with the cystlike spaces and horn cells typical of trichoepitheliomas. The most characteristic example of the latter (Fig. 6) was demonstrated in the naso-labial area, where trichoepitheliomas are most frequently encountered.

\section{Genetic Findings}

The mode of inheritance in each family was consistent with an autosomal dominant trait. There was no instance of a known consanguineous mating in either kindred.

The sex ratio among the affected was males: females, 14:15 in Family A, and 2:9 in Family B. It is impossible to exclude a chance relationship with sex in the latter family, particularly as in generations II and III the ratio of adults at risk was 17 females to 11 males.

Two instances of male-to-male transmission in Family A rule out the possibility of sex-linkage. The latter cannot be excluded in Family B, but the criteria of sex-linked dominant inheritance are not met. In both families females were more frequently severely affected than males, which again is contrary to the pattern of gene effect in sex-linked dominant conditions (e.g. vitamin D-resistant rickets and amelogenesis imperfecta).

Data on age of clinical onset were incomplete, but the observed range was from 10 to 25 years, and there was no sign of any anticipation effect. In Family $A$ the evidence suggested an age of onset during late childhood or early adolescence. Nine children of the affected members II.6 and IV.4 were examined. None had tumours and their ages varied from 3 to 17 years.

There was a considerable variation in the nature and extent of lesions among members of Family A; for instance III.5, aged 49, possessed large disfiguring tumours of the scalp, whereas her 80-yearold father, II.9, had minor manifestations in the form of two small scalp lesions and relatively slight facial involvement. In addition, IV.15, at approximately the same age at which III.5 was grossly disfigured by turban tumours, had a normal scalp, though she had several lesions around the nose which could be diagnosed clinically as trichoepitheliomas. Although both probands in Family B were similarly and extensively affected, the information on other relatives again suggested variation in expressivity.

In estimating penetrance it seemed justified to consider only the 26 subjects at risk in generation III of Family A, these being adults for whom information was relatively complete. Nine persons were affected and two others, III.9 and III.18, had probable involvement; the departure of the lower estimate $(9 / 26)$ from the proportion expected on a dominant hypothesis (13/26) does not reach significance at the $5 \%$ level. In addition there was no unequivocal instance of an unaffected bearer of the mutant gene in either pedigree.

\section{Discussion}

Clinical and histological variation is the rule in several autosomal dominant conditions characterized by multiple tumours involving epidermal structures on the head. Histological variation is marked in adenoma sebaceum (tuberous sclerosis), and facial lesions may incorporate hyperplastic sebaceous glands, or alternatively consist mainly of rudimentary hair organ structures. Similar variation is found in Von Recklinghausen's neurofibromatosis and the basal cell naevus syndrome (Gorlin, Vickers, Kelln, and Williamson, 1965; Clendenning, 1966).

In their fully expressed forms all the above syndromes show evidence of pathological involvement of body systems additional to the skin. Other systemic manifestations are not found in AncellSpiegler cylindromas or Brooke-Fordyce trichoepitheliomas, and so any distinction between each clinical category must be made on anatomical and histological grounds, principally by a demonstration of a hyaline membrane in tumours of the former type. There is evidence that the hyaline membrane in cylindromas is formed by polysaccharide secretory cells (Munger, Graham, and Helwig, 1962). Polysaccharide granules have been demonstrated in cells from a trichoepithelioma (Winkelmann and Muller, 1964), and Wolff and Holubar (1966) showed a close cytoenzymatic relation between these tumours and the normal hair organ. Although much remains to be done at a histochemical level it may be accepted that cylindromas show differentiation towards sweat glands, trichoepitheliomas 
towards hair structures, and syringomas towards sweat ducts.

It was concluded by Willis (1953) that subepidermal basal cell growths arising from pilosebaceous epithelium or sweat glands were extremely variable and could not be classified into distinct categories on clinical and histological evidence. Chalstrey (1955) was of the opinion that these multiple benign tumours of the skin and its epidermal appendages represented different manifestations of a single genetic defect.

While the pathogenesis of these lesions remains obscure it is not possible to exclude aetiological heterogeneity. For example, there are many welldocumented instances of isolated patients with a single cylindroma (Guggenheim, 1962) or trichoepithelioma (Gray and Helwig, 1963) and no suggestion of affected relatives. Such solitary tumours cannot be distinguished from inherited multiple lesions either clinically or histologically and raise the possibility of phenocopies. An additional point, illustrated by findings in Family $A$, is that persons with both types of lesions but principally trichoepitheliomas, may not be aware of small lesions in the scalp. The latter will then escape notice, particularly in hearsay descriptions.

Findings in the present study support the existence of a mutation inherited as an autosomal dominant and characterized by a variable phenotype, and demonstrate that clinical trichoephitheliomas may occur as the only type of lesion in a member of a family in which both entities are found. There are too many well-documented kindreds in which subjects were affected with both types of tumours to suggest the possibility of chance association of two separate autosomal mutations. A linkage hypothesis necessitates the further assumption of almost invariable coupling and seems intrinsically unlikely. There are families where Brooke-Fordyce trichoepitheliomas appear to segregate as the only type of lesion, but evidence of specific searches for scalp tumours in affected persons is much too incomplete to sustain the postulate of a separate genetic entity in these pedigrees. The production of varying phenotypes, as demonstrated in the present families, may be partially ascribed to the expression of a single mutation at apparently distinct tissue sites. If a single eponym is to be retained it should surely be that of Ancell, rather than Brooke, Fordyce, or Spiegler.

The question of penetrance is relevant to counselling in these families. From recorded data of varying quality, Guggenheim (1962) estimated penetrance as $60-80 \%$ and showed directly that penetrance was less than $100 \%$ by detecting no evidence of tumours in an 84-year-old woman who was an undoubted carrier on pedigree evidence. It may be noted that in Family B the question of non-penetrance was considered in the deceased but reputedly unaffected III.18. This was because his 30-year-old daughter, IV.38, was most alarmed over the significance of two small tumours in her scalp. However, it could be confirmed that the woman was unaffected because histological examination revealed that the tumours were uncomplicated sebaceous cysts with features quite distinct from those in cylindromas.

The significance of an apparent excess of affected females in reported material cannot be resolved at present. Extensive data on fully-investigated families are required. The matter is complicated by the possibility of incomplete penetrance and by a varying age of onset; the recorded range is from 5 to 50 years.

In the management of extensive and disfiguring scalp cylindromas there are two methods of treatment: $x$-ray therapy and surgical excision with skin grafting. The former method was used for III.12 of Family B and the latter method on her cousin III.27. Although the end result was judged as satisfactory in each case, $x$-ray therapy caused chronic ulceration and several months of discomfort, and the surgical procedure was undertaken without any unpleasant sequelae. Many reports support the conclusion from the above comparison that excision and grafting is the treatment of choice (e.g. Whiffen, 1963). Furthermore this method is free from the risk of induced neoplastic change.

\section{Summary}

It is concluded that the inherited, multiple, and benign tumours of the epidermal appendages, as described in this report, should be regarded as phenotypic variants of a single mutation, and that the most appropriate single eponym is that of Ancell. Histological characteristics depend on the site of the genetically determined lesion, and other descriptive terms (Ancell-Spiegler cylindromas, or turban tumours, and Brooke-Fordyce trichoepitheliomas) may be employed to indicate predominant tumour types. Inheritance is that of an autosomal dominant with variable expression. Onset of tumours is noted usually during the second decade and penetrance probably approaches $100 \%$ in adult life. There is no satisfactory evidence that the female sex is more commonly affected than the male.

We wish to thank Dr. V. A. McKusick for his advice and interest, Dr. F. Ellis for referring patients in Family A, and Drs. K. Crow and R. E. Hope-Simpson in Family 
B. Miss Kay Major provided invaluable assistance with geneological aspects of Family B. One of us (C.B.K.) was supported by the Post Graduate Medical Foundation, University of Sydney.

\section{REFERENCES}

Adamson, H. G. (1914). On the nature of rodent ulcer. Lancet, 1, 810.

Ancell, H. (1842). History of a remarkable case of tumours developed on the head and face. Med.-chir. Trans., 25, 227.

Billroth, T. (1859). Beobachtungen über geschwülste der Speicheldrüsen. Arch. path. anat. u. physiol., 17, 357.

Brooke, H. G. (1892). Epithelioma adenoides cysticum. Brit. f. Derm., 4, 269.

Chalstrey, L. J. (1955). Turban tumours. St. Bart's. Hosp. F., 59, 378.

Clendenning, W. E. (1966). Delineation of the basal cell nevus syndrome. In Basal cell nevus syndrome, Moderator N.I. Berlin. Ann. intern. Med., 64, 403.

Cockayne, E. A. (1933). Inherited Abnormalities of the Skin and its Appendages, p. 301. Oxford University Press, London.

Fordyce, J. A. (1892). Multiple benign cystic epithelioma of the skin. F. cutan. Dis., 10, 459.

Fuss, S. (1928). Spieglersche Tumoren. Arch. Derm. Syph. (Berl.), 155, 272.

Gorlin, R. J., Vickers, R. A., Kelln, E., and Williamson, J. J. (1965).

The multiple basal-cell nevi syndrome. Cancer (Philad.), 18, 89.
Gray, H. R., and Helwig, E. B. (1963). Epithelioma adenoides cysticum and solitary trichoepithelioma. Arch. Derm., 87, 102.

Guggenheim, W. (1962). Zur Klinik und Genetik der SpieglerBrookeschen Tumoren. Arch. Klaus-Stift. Vererb.-Forsch., 37, 129.

Ingels, A. E. (1935). Epithelioma adenoides cysticum with features of syringoma. Arch. Derm., 32, 75.

Jarisch (1894). Zur Lehre von den Hautgeschwülsten. Arch. Derm. Syph. (Berl.), 28, 163.

Kerl, W. (1930). Vererbung bei Spieglertumoren. ibid., 160, 55.

Luger, A. (1949). Das Cylindrom der Haut und seine maligne Degeneration. ibid., 188, 155.

Munger, B. L., Graham, J. H., and Helwig, E. B. (1962). Ultrastructure and histochemical characteristics of dermal eccrine cylindroma (Turban tumour). $f$. invest. Derm., 39, 577.

Savatard, L. (1938). Epithelioma adenoides cysticum. Brit. f . Derm., 50, 333.

Spiegler, E. (1899). Uber Endotheliome der Haut. Arch. Derm. Syph. (Berl.), 50, 163.

Watanabe, J. (1922). Ueber das Cylindrom und das Epithelioma adenoides cysticum. ibid., 140, 208.

Whiffen, J. D. (1963). Dermal cylindroma. Plast. reconstr. Surg., 31, 70 .

Willis, R. A. (1953). Pathology of Tumours, 2nd ed. Butterworth, London.

Winkelmann, R. K., and Muller, S.A. (1964). Sweat gland tumours. 1. Histochemical studies. Arch. Derm., 89, 827.

Wolff, K., and Holubar, K. (1966). Zur Histogenese des Trichoepithelioms. Eine enzymhistochemische Studie. Dermatologica (Basel), 133, 273.

Ziprkowski, L., and Schewach-Millet, M. (1966). Multiple trichoepithelioma in a mother and two children. ibid., 132, 248. 